\title{
Strategic advantages of high-rise construction
}

\author{
Natalya Yaskova ${ }^{1, *}$ \\ ${ }^{1}$ Moscow State University of Civil Engineering, Yaroslavskoye sh. 26, Moscow, 129337, Russia
}

\begin{abstract}
Traditional methods to assess the competitiveness of different types of real estate in the context of huge changes of new technological way of life don't provide building solutions that would be correct from a strategic perspective. There are many challenges due to changes in the consumers' behavior in the housing area. A multiplicity of life models, a variety of opportunities and priorities, traditions and new trends in construction should be assessed in terms of prospective benefits in the environment of the emerging new world order. At the same time, the mane discourse of high-rise construction mainly relates to its design features, technical innovations, and architectural accents. We need to clarify the criteria for economic evaluation of high-rise construction in order to provide decisions with clear and quantifiable contexts. The suggested approach to assessing the strategic advantage of high-rise construction and the prospects for capitalization of high-rise buildings poses new challenges for the economy to identify adequate quantitative assessment methods of the high-rise buildings economic efficiency, taking into account all stages of their life cycle.
\end{abstract}

\section{Introduction}

At all times, people tried to subordinate space and time to the demand to meet their growing needs. Progress manifested itself in the inevitable effect of the objective law of growing labor productivity, reducing time spent on the production of goods and requiring a structural arrangement of the living space. Consuming resources to structure the space, people created capital assets with various degrees of efficiency, solved the problems of accommodation and ensured functioning of industrial, infrastructural, social, and ecological frameworks of vital activity. During periods of economic growth, the rate of living space arrangement was accelerated, whereas the cost of the allocated resources often played a secondary role. The scale of goals determined the rate, not always (for example, in a socialist economy) putting cost-effectiveness at the forefront. Until recently, regardless of socio-economic structures, environmental consequences and quality of living space were not taken into account in achieving the goals. At present, it is impossible to ignore these factors. It is quite obvious that deteriorating living environment critically affects the

\footnotetext{
*Corresponding author: mcua3@yandex.ru
} 
standard of living, slows down the rate of development, hinders business activity $[1,2]$, therefore, creating conditions for crises.

A period of crises in all cases makes us reassess values, restructure natural and economic environment. This is particularly relevant for real estate, creating a framework of life and responsible for the quality of housing, transport, and common industrial infrastructure. Not only properties of real estate are subject to change, but also the processes of their formation and replacement of obsolete capital construction facilities [3]. At the same time, the laws of evolution dictate the need to create a steady trend of reducing resource consumption, distributed over all stages of life cycle, not only for manufactured products and provided services, i.e. the sphere of production, but also that of consumption, seeking to save operating costs and to increase the value of consumer goods, especially long-term ones [4].

\section{Materials and Methods}

One of the economic axioms is the existence of a direct connection between the duration of real estate life cycle and the need for giving it the maximum perspective advantage in relation to operational cost savings. This is especially relevant due to active formation of new megatrends in development. Drastic changes literally pervade everything: natural environment, including biosphere and land resources; production activities and services; research and educational activities; corporate standards and business models; organizational and economic management models; transport and supply systems; social sphere, including health care; public administration; financial and product markets; legal framework and existing institutions; socio-economic relations in the system "nature - society - man" etc.; personal needs for nutrition, recreation, communication, self-expression, entertainment, etc. New technological trends concern all sectors and spheres of national economy, creating a new picture of physical, biosphere, and digital world [5]. At the same time, convergence of new technologies occurs at all stages of the real estate life cycle. Thus, housing becomes not only "smart", replacing a number of traditional human functions, but also selfdeveloping, adaptive. Many experts [6] argue that modern computers are capable of selfdevelopment, which makes it difficult to predict which PC applications and when will arise. For instance, unmanned vehicles and drones, virtual assistants and translators, doctors, medicines and entertainment activities, foodstuffs, forms of communication, vertical cities and many other things that technical experts call "the surrounding mind". Laws of new wave of production and consumption development will inevitably affect the change of Man with its inherent new structure of needs and quality of life.

One of the most stable trends in modern social development is the growing urban population. Together with the population, the height of buildings also increases. Only in the last 15 years, the height of skyscrapers has increased from 270 to $350 \mathrm{~m}$. In this connection, Russia is by no means an exception, the country is a full participant in high-rise construction. Among 135 skyscrapers higher than $300 \mathrm{~m} 5$ buildings are located in the Russian Federation. Historically, the leading Russian cities' verticals consisted of belfries, churches, minarets, etc. As early as in the $18^{\text {th }}$ century, Russia was a leader in high-rise buildings. In Saint Petersburg, the spire of the Peter and Paul Fortress was $122 \mathrm{~m}$ height, being the highest one in Europe. The form of modern Kremlin should have changed significantly, as the height of the Palace of Soviets, according to the original conception, should have been $400 \mathrm{~m}$. The construction plans were disrupted by war, but seven high-rise buildings were established. Thus, contrary to the prevailing illusion of Russia's chronic underdevelopment in high-rise construction, the country has always participated in the race for high-rises [7].

In terms of design feature and space-planning solutions, high-rise construction has been 
sufficiently well investigated [8]. It is obvious that high-rise buildings must be safe, smart, and energy-efficient. In terms of economic evaluation, these buildings are traditionally considered to be much more expensive as compared to traditional ones. It is true for the most part, but it is necessary to take into consideration other aspects that can alter such unambiguous conclusions.

First of all, a consumer behavior is changing. A new generation of buyers enters the real estate market, who have grown up in a new information environment on the one hand, one the other - they impart much greater importance to design, information and communication quality of life environment; and also they have certain ambitions and propensity to experiment. This creates an increased demand for accommodation in high-rise buildings.

Secondly, to assess the economic efficiency of high-rise buildings and any other real estate, it is necessary to take into account their whole life cycle. The modern technologies of real estate construction and operation allow for saving to $30 \%$ of the life cycle cost component [9]. However, lower operational costs save not only money, but also the time of owners for making utility payments, telemetrically reading the data of water and electricity meters.

Thirdly, technological innovations solve critical mass of technical problems associated with high-rise buildings, such as the problem of vertical transport, water supply, energy and heat supply, parking spaces, wind load, etc.; with complication of tasks, their price in most cases decreases. Thus, for instance, technology of horizontal and vertical movement of people in buildings using a levitation method (tested in a German city of Rottweil). The system does not use cables, does not require designing a core for elevators in the center of high-rise building, which ensures a much more maneuverable approach to flat arrangement, allowing different buildings linking and creating a new space design.

Fourthly, improving environmental friendliness of future cities is a reality observed all over the world. The cost estimate of environmental friendliness is not only possible, but it is already widespread, for example, by housing buyers. They "vote with a ruble", buying real estate for a price of 20-25\% more expensive, where there are park areas and clean air. In this regard, it must be noted that, unlike traditional buildings, high-rise development provides more free space for green plantations, leaving the land for parks and public areas, etc.

Fifthly, when planning a modern life framework, one should think about the perspective; the today's needs may change drastically in the future. For instance, the answer to the question about large-scale parking necessity is rather negative. With the development of car-sharing, unmanned vehicles, the number of parking spaces can be reduced significantly. The approach to retail, public and other spaces can also change. If in the first case, online shopping will reduce the functional shopping areas, in the second case, the demand will clearly increase.

All these factors should be taken into account when assessing high-rise buildings' economic efficiency. Meanwhile, a modern developer is aimed at getting quick profit. As a result, they continue using outdated building format with a low standard of life, which, surely, contradicts the interests of State and society. Moreover, many examples of economically successful skyscrapers worldwide demonstrate a very high system-dynamic building effect. For instance, Burj Khalifa in Dubai. The tower is capital intensive, and taking into consideration the fact that the final construction stage took place in global crisis, the real estate turned to be unprofitable. At the same time, the tower became part of a largescale construction project, consisting of many surrounding objects of various functional purposes. Regardless of the real estate type - commercial, banking, sports \& entertainment or residential - the view of the future tower ensured positive dynamics of efficiency. The mega-tower of Burj Khalifa has paid off, and the area around it has made and continues to make profit for its developer - EMAAR. The mentioned example also emphasizes that 
criterion for assessing economic efficiency of high-rise buildings in modern environment must "capture" the comprehensive effects during the entire life cycle of high-rise buildings.

\section{Results}

The main theoretical premise for assigning the integrated economic efficiency of high-rise construction is identifying the strategic orientation of construction. It means that we cannot neglect how the urban environment will change or what the effect of renovation will be, what innovations will be implemented or how the urban environment will react, etc. Bearing in mind that, according to F. Nikandrov, the Chief Architect of GORPROEKT, "high-rise construction is always a challenge" (financial, constructive, organizational, etc. challenges), its strategic focusing becomes the main condition for launching the project as early as at a project stage. It is necessary to emphasize that the competitive advantage, fixing the economic efficiency of a high-rise construction project at a given time, not only poorly reflects the outlook, but is also based on numerous assumptions in its calculation part, which does not meet the requirements of new social development context. In view of the above mentioned, from the author's point of view, the strategic advantage is a concept reflecting the contemporary contexts of high-rise construction as discussed above. The latter is expedient, if it corresponds to the trend of dynamically changing social needs and preferences in terms of the configuration and structure of life framework. Note that strategic interests of creating a comfortable urban environment form the priority with regard to assessment judgments on high-rise real estate economic efficiency.

As for the tools to provide the strategic advantage from the point of view of optimal adaptation of skyscrapers to the urban development priorities, let us mention that they represent a combination of mechanisms, models, and technologies for assessing real estate economic efficiency at all stages of its life cycle.

From the economic point of view, common approach to real estate life cycle cost evaluation [9] is based on the understanding of aggregate costs of real estate owner. With reference to high-rise buildings, in general, these are cost of their designing, construction, operation, and disposal. Note that the costs at the operation stage are up to $75 \%$ of the total. Those of the construction stage sometimes are up to $20 \%$. Accordingly, designing and disposal will make from 5 to $10 \%$ of the total real estate costs. A case study showed that, in high-rise construction, possible savings at designing stage, even using information technology, are insignificant. Construction stage also features a high capital intensity and technological discipline. As a result, the main cost savings reserve lies in operational costs.

The modern innovative context presupposes the construction of energy-efficient and environmentally friendly buildings. The studies showed that the average resource economy when using modern technology reaches $30 \%$. In this case, everything else being equal, absolute value of economic efficiency $\left(E_{l c}^{a}\right)$ of a modern high-rise building can be estimated as

where:

$$
E_{l c}^{a}=\sum z_{l c}^{\sigma}-\sum z_{l c}^{i n}
$$

$\sum Z_{l c}^{\sigma}$ are the cumulative life cycle costs of a high-rise building, constructed without the use of modern technology;

$\sum Z_{l c}^{i n}$ are the cumulative life cycle costs of a high-rise building, constructed with the use of modern technology.

In general, savings will be more than $20 \%$ in the current structure of life cycle costs. Thus, for a property owner, the effect is translated in saving total costs. But, as shown by 
the study, modern ownership contexts should not be limited only to expense component. Market valuation of high-rise buildings is important, i.e. its capitalization (over time, it becomes increasingly important). Capitalization of high-rise buildings is an increase in their value over time. Our study of capitalization processes showed that they have inherent rules, as shown in the Fig. 1.

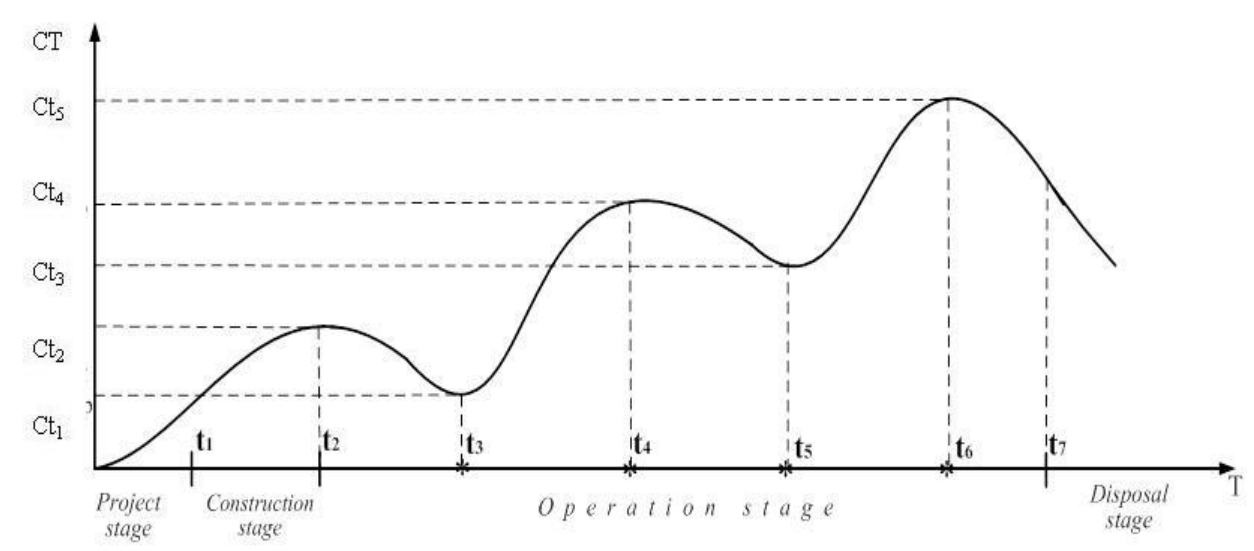

Fig. 1. High-rise buildings decapitalization rule

CT is high-rise real estate market price;

$\mathrm{Ct}_{1}$ is actual price of property at the moment ( $\left.\mathrm{t} 2\right)$ of putting into service;

$\mathrm{Ct}_{2}$ is actual price of property at the moment ( $\mathrm{t} 3$ ) of launching the overhaul;

$\mathrm{Ct}_{3}$ is actual price of property at the moment (t4) of the end of the overhaul;

$\mathrm{Ct}_{4}$ is actual price of property at the moment ( $\mathrm{t} 5$ ) of renovation / restructuring;

$\mathrm{Ct}_{5}$ is actual price of property at the moment (t6) of the end of;

$(\mathrm{t} 2 \div \mathrm{t} 3),(\mathrm{t} 4 \div \mathrm{t} 5),(\mathrm{t} 6 \div \mathrm{t} 7)$ are periods of decapitalization.

As follows from the diagram, a strategically focused life cycle must include some stages in property operational phase. The following relationships characterize them:

$$
\mathrm{Ct}_{1}<\mathrm{Ct}_{2}<\mathrm{Ct}_{3}<\mathrm{Ct}_{4}<\mathrm{Ct}_{5}
$$

\section{Conclusion}

Thus, high-rise objects capitalization is the result of ensuring their normal operation, as well as real estate overhaul and restructuring. For its owner, it is of fundamental importance that additional costs for capitalization activities were lower than the increment in value at all phases and stages of its life cycle. In this case, economic benefits of saving life cycle costs are supported by high-rise real estate capitalization factors. Moreover, the owner should, already at a startup stage, evaluate economic potential of overhaul and reconstruction, thus ensuring the strategic advantage of a high-rise building in the long term.

\section{References}

1. V.V. Gluhov, I.V. Ilin, V.I. Koposov, A.I. Levina, Asian Social Science, 10 (24), pp 209- 216 (2014) DOi- 10.5539/ass.v10n24p209

2. N. Yaskova, Modern formats of the strategy of urban real estate development. Scientific review. 7-1. p. 392-396 (2014)

3. N. Yaskova. Evolution of the development of investment and construction activities. Bulletin of the Irkutsk State Technical University. 1 (60). P. 178-186. (2012) 
4. I.G. Lukmanova, N. Yaskova. Development of the scientific foundations of the evolutionary economy in the current conditions of investment and construction activity. Economics of construction. 4 (28). p. 13-19. (2014)

5. K. Schwab. The Fourth Industrial Revolution. M., Eksmo, 208 p. (2016)

6. V.S. Kazeikina, S.A. Baronina The cost of owning residential real estate at the total cost in the life cycles of reproduction as the basis for energy efficiency management / under the general. Ed.. Astana, 212 p. (2015)

7. V.V. Peshkov, N. Yaskova. Myths and reality of modern administration. Ekonomichny chasopis-XXI. 3-4. - P. 32-36. (2015) 